\section{Examination of the effect on life satisfaction of sportsmen's of job satisfaction and sport satisfaction and organizational commitment feelings}

Sporcuların iş tatmini spor tatmini ve örgütsel bağlılık duygularının yaşam tatmini üzerindeki etkisinin incelenmesi

\author{
Yusuf $\operatorname{Can}^{1}$
}

\section{Abstract}

This research has two main purposes. The first was to examine the effect of athletes' job satisfaction, sports satisfaction and organizational commitment on life satisfaction and the second one was to examine whether there was a significant differences between job satisfaction, sports satisfaction and organizational commitment of the athletes who had low and high life satisfaction.

This research was carried out on a total of 669 athletes who were randomly selected from 20 different provinces of Turkey and who voluntarily agreed to participate in the study. Job satisfaction, sport satisfaction, organizational commitment and life satisfaction scales were used as data collection tools in the research.

As a result of the research, it was determined that job satisfaction, sports satisfaction and organizational commitment explained $43.2 \%$ of life satisfaction. Among these three variables organizational commitment (beta $=.362$ ) is variable which effect the life satisfaction most. In response to the second question, it was also determined in the study that there was a significant difference between job satisfaction, life satisfaction and organizational commitment of the athletes' with high and low life satisfaction. Thus, three important variables
\end{abstract}

Özet

$\mathrm{Bu}$ araştırmanın iki temel amacı vardır. Birincisi, sporcuların iş tatmini, spor tatmini ve örgütsel bağlılık duygularının yaşam tatmini üzerindeki etkisini incelemek, ikincisi ise, yaşam tatmini düşük ve yüksek olan sporcuların iş tatminleri, spor tatminleri ve örgütsel bağllıkları arasında anlamlı farklılıkların bulunup bulunmadığını incelemektir.

$\mathrm{Bu}$ araştırma, Türkiye'nin 20 farklı ilinden tesadüfi örnekleme yöntemiyle seçilmiş ve araştırmaya gönüllü olarak katılmayı kabul etmiş olan toplam 669 sporcu üzerinde yapilmıştır. Araştırmada veri toplama aracı olarak, iş tatmini, spor tatmini, örgütsel bağlllık ve yaşam tatmini ölçekleri kullanılmıştır.

Araştırma sonucunda, iş tatmini, spor tatmini ve örgütsel bağllliğın yaşam tatminini \%43.2 açıkladığ 1 belirlenmiştir. $\mathrm{Bu}$ üç değişkenden yaşam tatminini en çok etkileyen değişken ise örgütsel bağlllıktır (beta= .362). Araştırmada ayrica ikinci soruya cevap olarak, yaşam tatmini yüksek ve düşük olan sporcuların iş tatminleri, yaşam tatminleri ve örgütsel bağllilkları arasında anlamlı farklliklar bulunmuştur. Böylece sporcuların yaşam tatminini açılayan üç önemli değişken literatüre kazandırılmıştır.

\footnotetext{
${ }^{1}$ Doç. Dr., Muğla Sitkı Koçman Üniversitesi Spor Bilimleri Fakültesi Spor Yöneticiliği Bölümü, yusufcan@,mu.edu.tr
} 
Can, Y. (2016). Sporcuların iş tatmini spor tatmini ve örgütsel bağlılık duygularının yaşam tatmini üzerindeki etkisinin incelenmesi. Journal of Human Sciences, 13(3), 5248-5256. doi:10.14687/ihs.v13i3.4237

explaining the life satisfaction of the athletes were brought in literature.

Keywords: Life satisfaction; sport satisfaction; job satisfaction; organizational commitment.

(Extended English abstract is at the end of this document)
Anahtar Kelimeler: Yaşam tatmini; iş tatmini; spor tatmini; örgütsel bağllik.

\section{GİRİŞ}

Bireyler, birer sosyal varlık olarak yaşamlarını sürdürürken farkında olarak veya olmayarak görev aldıkları gruplardaki statülerinin ve rollerinin etkisi altındadırlar. Bu statü ve roller grup içinde genellikle belirgindir. Bu grupların kendilerine özgü iletişim sistemleri, kültürleri, sosyal ağları, liderleri ve alt kültürleri vardır. Bireyler de, bu grup dinamiklerine uyumlu davranmak zorunda hisserlerler kendilerini. Bazen de gruplar arasındaki roller birbirine geçişim yapar ve birey bazen istenmeyen davranışlar sergiler. Çünkü aradaki sınır bazı gruplar açısından belirsizdir. Sporcu bir kimliğe sahip birey, sosyal yaşamında da sporculuk kimliği ile ön plana çıkabilir. Çeşitli gruplara giren birey bu gruplarda büyük bir ihtimalle sporcu kimliği ile tanınacaktır.

Sporcular genel olarak iki nedenle spor yapiyorlardır ve iki neden sporcunun statü ve rolünü de kulübünde tanımlyyordur. Birinci neden ekonomiktir. Sporcular geçimlerini temin etmek amaciyla profesyonel ya da amatör olarak spor yapıyor, becerisini, kabiliyetini veya tecrübesini ortaya koyarak para kazaniyordur. İkinci neden ise, sosyal tatmindir. Bireyler rahatlamak amaciyla, streslerini azaltmak amacıyla veya hobi olarak spor yapıyordur. Birinci amaç ile ikinci amaç arasında önemli bir farklılık vardır. Birinci amaçta spor bir meslek haline gelmiştir ancak ikinci amaçta spor bir meslek değil bir hobi alanıdır. Birinci amaç grubunda yer alan sporcuların sosyal yaşamları ile sportif yaşamlarının iç içe geçmesi, rollerin karışması, rollerin çatışması veya iki hayatın birbirini etkilemesi daha muhtemeldir. Temel olarak bu iki ayrım ortaya konulmaz ise bu çalışmanın ve sporun psiko-sosyal alanları ile ilgili olarak yapılacak diğer çalışmaların yorumlanması güçleşecektir. Bu çalışmada spor bir meslek olarak kabul edilmiştir.

$\mathrm{Bu}$ çalışmanın temel konusunu teşkil eden yaşam tatmini, psikologların, sosyologların, örgütsel davranış bilimcilerinin, davranış bilimcilerin ilgi odağı olmuş konulardan biridir. Yaşam tatmini denildiğinde belirl ibir duruma ilişkin değil genel olarak yaşamın her alanındaki tatmin kastedilir. Yaşam tatmini kişinin kendi hayatının hoşlandığ1 ya da hoşlanmadığ1 yönlerin özet bir değerlendirmesidir (Heller and at all, 2003). Bir başka tanımla yaşam tatmini kişinin boş zaman ve diğer iş dışı zaman olarak tanımlanan yaşamın bütününe gösterdiği duygusal tepkisi ya da tutumudur. $\mathrm{Bu}$ açıdan değerlendirildiğinde yaşam tatmini bir tutum olarak görülebilir. Bireyin yaşama ilişkin tepkisidir, beklentileri ile bu beklentileri karşılama derecesi arasındaki pozitif farktır. Yukarıda bahsedilen rollerin karışması yaşam tatminini doğrudan etkileyen unsurların başında gelmektedir. Bireylerin iş yaşamlanı, sosyal yaşamlan, arkadaşlarıyla olan yaşamı kısaca çeşitli gruplar içindeki yaşamı genel olarak bireyen yaşama ilişkin algılamasını ve dolayısıyla tatminini etkiler.

İş tatmini bireyin işine veya iş tecrübelerine ilişkin yaptı̆̆ değerlendirme sonucunda ulaştı̆̆1 pozitif duygulardır (Locke, 1976). Bu çalışmada, sporcuların işi sporculuktur. Dolayısıyla sporcuların yaptıkları iş nedeniyle bir tepkileri olacaktır veya yaptıkları işle ilgili bir değerlendirme yapacaklar, pozitif veya negatif bir duyguya ulaşacaklardır.

Spor tatmini ise, sadece spor yapan bireyler açssından mümkün olabilecek bir tatmindir. Sporcular açısından iş ile spordan alınan tatmin birbirinden farklıdır. Bir sporcu takımda kendisine verilen görevden memnun olabilir, çünkü iş, içinde ücretin, çalışma koşullarının, antrenman koşullarının, psikolojik değerlendirmelerin, verilen görevin dışarıdan görünüşünü de içeren bir kavramdır. Ama spor tatmini bireyin kendisi ile ilgilidir. Verilen işin iyi yapılıp yapılmadığı veya 
Can, Y. (2016). Sporcuların iș tatmini spor tatmini ve örgütsel bağlllık duygularının yașam tatmini üzerindeki etkisinin incelenmesi. Journal of Human Sciences, 13(3), 5248-5256. doi:10.14687/ihs.v13i3.4237

verilen görevde başarılı olup olunamadığı ile ilgili genel değerlendirmelerdir. Birey işinden memnun olabilir ancak oyunundan memnun olmayabilir. Bu iki tatmin birbirini etkileyebilir veya etkilemez. Spor tatmini sporcuların yaptıklanı ya da ilgilendikleri alandaki sportif tecrübelere ilişkin pozitif duygularidır (Scanlan vd., 1993).

Örgütsel bağlll1k, bireyi örgüte bağlayan psikolojik bir durumdur (Meyer ve Herscovitch, 2001; Wasti, 2002),). Meyer ve Allen, örgütsel bağlllı̆̆ın üç boyutta ele almaktadır (Meyer ve Allen, 1984, Allen ve Meyer, 1990). Birinci boyut duygusal bağlllıktır. Duygusal bağll1ık örgütün bireyi desteklemesi veya yakınlık göstermesi sonucu bireyin örgütte kalma düşüncesidir. Bu durumda birey örgütün kendisine yaptuğ destekten duygusal olarak etkilenmektedir ve örgütten ayrildığında kendini huzursuz hissedecektir. Dolayısıyla da örgütten ayrilmayı düşünmeyecektir (Meyer ve Allen, 1991). İkinci boyut, devam bağlllı̆̆ıdır. Bu bağllıkta, birey dışarıda başka alternatifi olmadığı, başka alternatiflerin psikolojik maliyetinin yüksek olacağını düşündüğü veya ekenomik olarak gelirinin azalacağını düşündüğü için örgütte kalma kararı vermektedir (Meyer ve Allen, 1991). Üçüncü ve son boyut normatif bağlllıktır. Bu bağlllık türünde birey, örgütte yaptığ1 görevi etik nedenlerle bırakamayacağını düşündüğü, o işi kendisinin yapması gerektiğini, bırakıp gittiğinde bunun uygun olmayacağını düşündüğü için örgütte kalmaya devam etmektedir (Meyer ve Allen, 1991, Allen ve Meyer 1990). Her üç boyutta da birey örgütte kalmaya devam etmektedir. Herhangi bir kulüpfederasyon veya ülke adına aktif sportif yaşamı tercih eden bireyler yani sporcular, temsil ettikleri takımlarıyla duygusal bağlllık, devam bağlılığı ve normatif bağlılık duygularıyla takımlarına bağlı kalmayı arzu eder. Bu bağlılık duygusu, sporcuların aktif spor yaşamını dengeleyen önemli bir güç kaynağını oluşturur. Dolayısıyla her sportif başarıda bu bağlllik duygusu güçlenir, her başarısızlık durumunda ise, bu bağlllık duygusu sporcunun sığınacağı bir limana dönüşür.

$\mathrm{Bu}$ araştırmanın iki temel amacı vardır. Birincisi, sporcuların iş tatmini, spor tatmini ve örgütsel bağllllk duygularının yaşam tatmini üzerindeki etkisini incelemek, ikincisi ise, yaşam tatmini düşük ve yüksek olan sporcuların iş tatminleri, spor tatminleri ve örgütsel bağlllıkları arasında anlamlı farklılıkların bulunup bulunmadığını incelemektir.

\section{YÖNTEM}

Araştırma 20 ilden çeşitli spor branşlarındaki kolayda örnekleme yoluyla seçilmiş 669 sporcu ile yürütülmüştür. Araştırmaya katılanların \% 72.4'ünün erkek, \% 93.2'sinin bekar, \% 52.5'inin orta öğretim mezunu ve \% 87.6'sının spor dışında gelir getirici bir işte çalışmadıkları görülmektedir. Grubun yaş ortalamas 19.4 \pm 4.7 , ortalama spor yaşı ise $6.39 \pm 4.2$ dir. Örneklemin diğer özellikleri Tablo 1'de gösterilmiştir.

Tablo 1: Demografik Özellikler

\begin{tabular}{|c|c|c|}
\hline Cinsiyet & $\bar{f}$ & $\%$ \\
\hline Erkek Sporcu & 484 & 72.4 \\
\hline Kadin Sporcu & 185 & 27.6 \\
\hline Toplam & 669 & 100.0 \\
\hline Medeni Durum & $f$ & $\%$ \\
\hline Evli & 45 & 6.8 \\
\hline Bekar & 624 & 93.2 \\
\hline Toplam & 669 & 100 \\
\hline Ë̆itim Düzeyi & $f$ & $\%$ \\
\hline İlköğretim & 90 & 13.4 \\
\hline Orta öğretim & 351 & 52.5 \\
\hline Yüksek öğretim & 208 & 31.1 \\
\hline Lisansüstü & 20 & 3.0 \\
\hline Toplam & 669 & 100 \\
\hline Spor Dişında Geliri Olup Olmadĭ̆1 & $f$ & $\%$ \\
\hline Spor dışında gelir getirici bir işte çalışanlar & 83 & 12.4 \\
\hline Spor dişında gelir getirici bir işte çalışmayanlar & 586 & 87.6 \\
\hline Toplam & 669 & 100.0 \\
\hline
\end{tabular}


Can, Y. (2016). Sporcuların iş tatmini spor tatmini ve örgütsel bağlılık duygularının yaşam tatmini üzerindeki etkisinin incelenmesi. Journal of Human Sciences, 13(3), 5248-5256. doi:10.14687/ihs.v13i3.4237

Ankette kullanılan ölçekler:

İs tatmini: İş tatmini Warr ve arkadaşlarının geliştirdiği ölçeğin sporculara uyarlanması ile ölçülmüştür (Warr vd., 1979). Ölçekte işin değişik unsurlarına ilişkin 8 ifade bulunmaktadır ve 5’li likert sistemine dayanmaktadır. Ölçeğin güvenilirliği yani cronbach alfa değeri .77'dir.

Yaşam tatmini: Diener ve arkadaşları tarafindan geliştirilen ve 5 ifadeden oluşan bir ölçek kullanılmıştur (Diener vd., 1985). Ölçek 5’li likert tipidir ve bu araştırmada cronbach alfa değeri .83'dür.

Spor tatmini: Spor tatminini ölçmek için Rosich tarafindan geliştirilmiş 8 ifadeden oluşan ve 5’li likert sistemine dayanan bir ölçek kullanılmıştır (Rosich, 1999). Ölçeğin güvenilirliği .78 olarak hesaplanmıştır.

Örgütsel Bağlılık: Örgütsel bağlllık O’Reilly ve Chatman tarafindan geliştirilmiş ve 5 ifadeden oluşan bir ölçekle ölçülmüştür. Ölçek yine 5'li likert sistemine dayanmaktadır ve ölçeğin güvenilirliği bu araştırmada 80 olarak hesaplanmıştır.

\section{BULGULAR}

Araştırmaya katılan sporcuların iş tatmini, spor tatmini ve örgütsel bağlllık duygularının yaşam tatminini açıklama oranı için regresyon analizi yapılmıştır. Regresyon analizi sonucu aşağıda iki tablo halinde verilmiştir:

\section{Regresyon Analizi}

Tablo 2: İş tatmini, spor tatmini ve örgütsel bağlllı̆̆ın yaşam tatmini üzerindeki etkisine ilişkin regresyon analizi

\begin{tabular}{lccccc}
\hline Bağımsız Değişkenler & $\mathbf{R}$ & $\mathbf{R}^{2}$ & $\begin{array}{c}\text { Düzeltilmiş } \\
\mathbf{R}^{2}\end{array}$ & $\begin{array}{c}\text { Tahminin } \\
\text { Standart Hatası }\end{array}$ & $\mathbf{F}$ \\
\hline İş tatmini+spor tatmini+örgütsel bağlılık & .659 & .434 & .432 & .481 & 170.271 ** \\
\hline ** $<.001$, Bağıml değişken : Yaşam tatmini & & & & &
\end{tabular}

Tablo 3: Coefficient tablosu

\begin{tabular}{lcccc}
\hline & $\begin{array}{c}\text { Standardize Edilmemiş } \\
\text { Coefficient B }\end{array}$ & $\begin{array}{c}\text { Std. } \\
\text { Hata }\end{array}$ & $\begin{array}{c}\text { Standardize Edilmiş } \\
\text { Beta }\end{array}$ & t \\
\hline İş tatmini & .331 & .031 & .172 & $4.840^{* *}$ \\
Spor tatmini & .240 & .034 & .272 & $8.052^{* *}$ \\
Örgütsel bağllilk & .182 & .040 & .362 & $9.777^{* *}$ \\
\hline$* *$ p $<.001$ & & &
\end{tabular}

Yapılan analiz sonucunda her üç bağımsız değişkenin de yaşam tatmini üzerinde etkili olduğu görülmektedir. İş tatmini-spor tatmini ve örgütsel bağllllk üçü birlikte yaşam tatminini \% 43.2 oranında açıklamaktadır. Beta katsayılarına bakıldığında ise tüm etkilerin pozitif olduğu ve en büyük etkinin örgütsel bağlllık olduğu görülmektedir.

Araştırmanın ikinci temel sorusu yaşam tatmini düşük ve yüksek olan sporcuların iş tatminleri, spor tatminleri ve örgütsel bağllılılarının farklı olup olmadığı idi. Bunu yapabilmek için örneklem yaşam tatmini açısından iki gruba ayrılmıştır. Ortalamanın altında yaşam tatmine sahip olanlar ve ortalamanın üstünde yaşam tatminine sahip olanlar ayrı ayrı kodlanmıştır. Böylece örneklem yaşam tatmini açısından iki gruba ayrılmıştır. Bu aşamada farklılıkları analiz edebilmek için $\mathrm{t}$ testi yapılmalıdır. Yapılan $\mathrm{t}$ testi sonuçları aşağıdaki tablolarda ayrı ayrı gösterilmiştir. 
Can, Y. (2016). Sporcuların iș tatmini spor tatmini ve örgütsel bağlllık duygularının yașam tatmini üzerindeki etkisinin incelenmesi. Journal of Human Sciences, 13(3), 5248-5256. doi:10.14687/ihs.v13i3.4237

\section{Farklulk Analizi (t testi)}

Tablo 4: Yaşam tatmini düşük ve yüksek olanların iş tatminleri arasındaki farklılık

\begin{tabular}{l|cccc}
\hline \multicolumn{1}{c|}{ Değişkenler } & Ortalama & $\begin{array}{c}\text { Standart } \\
\text { Sapma }\end{array}$ & t değeri & $\begin{array}{c}\text { Anlamlılık } \\
\text { Düzeyi }\end{array}$ \\
\hline Yaşam tatmini düşük olanların iş tatmini & 2.85 & .36 & \multirow{2}{*}{-30.490} & 0.000 \\
\hline Yaşam tatmini yüksek olanların iş tatmini & 3.87 & .42 & \\
\hline
\end{tabular}

Yaşam tatmini düşük olan sporcuların iş tatmin duyguları ile yaşam tatmini yüksek olan sporcuların iş tatmini duygusu arasında anlamlı bir fark bulunmuştur $(\mathrm{p}<0.001)$. Bu sonuca göre yaşam tatmini yüksek olan sporcuların iş tatmin duyguları yaşam tatmini düşük olanlardan daha yüksek düzeydedir.

Tablo 5: Yaşam tatmini düşük ve yüksek olanların spor tatminleri arasındaki farklılık

\begin{tabular}{l|cccc}
\hline \multicolumn{1}{c|}{ Değişkenler } & Ortalama & $\begin{array}{c}\text { Standart } \\
\text { Sapma }\end{array}$ & $\begin{array}{c}\boldsymbol{t} \\
\text { değgeri }\end{array}$ & $\begin{array}{c}\text { Anlamlılık } \\
\text { Düzeyi }\end{array}$ \\
\hline Yaşam tatmini düşük olanların spor tatmini & 3.40 & .62 & \multirow{2}{*}{-8.382} & 0.000 \\
\hline Yaşam tatmini yüksek olanların spor tatmini & 3.85 & .71 & & \\
\hline
\end{tabular}

Yaşam tatmini düşük olan sporcuların spor tatmin duyguları ile yaşam tatmini yüksek olan sporcuların spor tatmini duygusu arasında anlamlı bir fark bulunmuştur $(\mathrm{p}<0.001)$. Bu sonuca göre yaşam tatmini yüksek olan sporcuların spor tatmin duyguları yaşam tatmini düşük olanlardan daha yüksek düzeydedir.

Tablo 5: Yaşam tatmini düşük ve yüksek olanların örgütsel bağlllıkları arasındaki farkll1ık

\begin{tabular}{c|cccc}
\hline Değişkenler & Ortalama & $\begin{array}{c}\text { Standart } \\
\text { Sapma }\end{array}$ & $\begin{array}{c}\boldsymbol{t} \\
\text { değgeri }\end{array}$ & $\begin{array}{c}\text { Anlamlılık } \\
\text { Düzeyi }\end{array}$ \\
\hline Yaşam tatmini düşük olanların örgütsel bağllık & 3.16 & .71 & \multirow{2}{*}{-12.118} & 0.000 \\
\hline Yaşam tatmini yüksek olanların örgütsel bağlılık & 3.89 & .58 & \\
\hline
\end{tabular}

Yaşam tatmini düşük olan sporcuların örgütsel bağlllık duyguları ile yaşam tatmini yüksek olan sporcuların örgütsel bağllik duygusu arasında anlamlı bir fark bulunmuştur $(\mathrm{p}<0.001)$. Bu sonuca göre yaşam tatmini yüksek olan sporcuların örgütsel bağl1lık duyguları yaşam tatmini düşük olanlardan daha yüksek düzeydedir.

\section{TARTIŞMA VE SONUÇ}

Yaşam tatminini etkileyen faktörleri belirlemeye yönelik ve sporcular açısından iş tatmininin, spor tatmininin ve örgütsel bağlılıklarının yaşam tatminleri üzerindeki etkisini belirlemek amacıyla yapılan bu çalışma amacına ulaşmıştır. Araştırmada yaşam tatminini etkileyen üç değişken aşağıdaki şekilde gösterilmiştir. 
Can, Y. (2016). Sporcuların iş tatmini spor tatmini ve örgütsel bağlılık duygularının yaşam tatmini üzerindeki etkisinin incelenmesi. Journal of Human Sciences, 13(3), 5248-5256. doi:10.14687/ihs.v13i3.4237

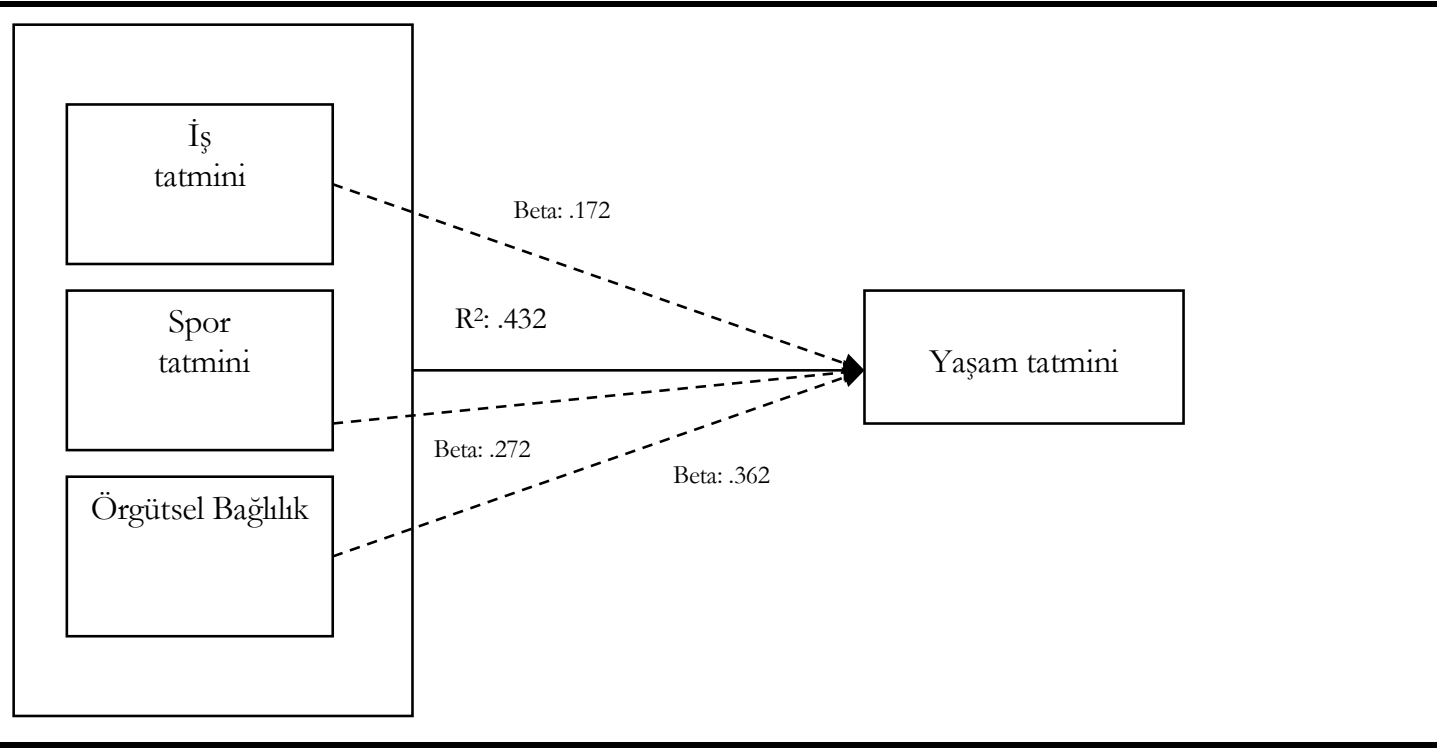

İş tatmini, spor tatmini ve örgütsel bağllllk bir arada regresyon analizine tabi tutulmuş ve bu üç değişkenin birlikte yaşam tatminini açılklama derecesi \% 43.2 olarak hesaplanmıştur. Yaşam tatmini etkileyebilecek çok sayıda değişken olabileceği dikkate alındığında açıklama derecesinin yüksek olduğu düşünülebilir. Yaşam tatmini üzerindeki en büyük etki örgütsel bağllliğın etkisidir. Araştırmanın yapıldığ1 örneklem için düşünüldüğünde sporcuların kulüplerine olan bağlllı̆̆1 onların yaşam tatminlerini etkilemektedir. Örgütlerine bağlanan bireyler adeta yaşama da bağlanmaktadır. Yaşamdan elde etmeyi planladıklarını elde ettiklerini düşünmeye başlamaktadır. Bu yorumda göz ardı edilmemesi gereken temel husus yaşam tatmininin hayatun çeşitli dönemlerinde düşebileceği veya yükselebileceğidir.

Sporcular açısından düşünüldüğ̈nnde spor tatmini yaşam tatminini etkileyen faktörlerden bir diğeridir. Giriş bölümünde de bahsedildiği üzere sporcular açısından iş tatmini ile spor tatmini birbirinden farklı iki tatmini ifade etmektedir. Spor tatmininin yaşam tatminini etkileyeceği tahmin edilen bir sonuç olmakla birlikte örgütün yapılan spordan ve takım içerisindeki görevden (iş) daha önemli olması sonucu düşündürücü bir sonuçtur. Örgüt veya kulüp spor tatmininden daha önceliklidir.

Son olarak iş tatmini de yaşam tatminini etkileyen faktörlerden biridir. Bu sonuç da beklenen sonuçlardan biridir. Çünkü, yaşam tatminini olşturan faktörlerden biri de bireylerin iş yaşamlarıdır, işlerinden aldıkları ücret veya iş arkadaşlarıyla ilişkiler vb. gibi.

Literatürde iş tatmini ile yaşam tatmini arasındaki ilişkileri ele alan çok sayıda araştırma bulunmaktadır. 1970'li yıllardan itibaren yaşam tatmini ile iş tatmini arasındaki ilişkiler ele alınmaktadır. Yapılan araştırmalar çelişkilidir (Judge ve Watanabe, 1993; Judge vd., 2001; Kreitner ve Kinicki 2001; Spector 1997).

$\mathrm{Bu}$ çelişkili sonuçlar bilim adamlarını üçlü bir model oluşturmaya sevketmiştir. Yaşam tatmini ile iş tatmini arasındaki ilişkiler genellikle üç model kapsamında ele alınmaktadır. Yayılma modeli, ayırma modeli ve telafi etme modeli. Yayılma modeli iş tatmini ile yaşam tatmini arasında pozitif yönlü ilişkilerde, ayırma modeli ilişkisizlikte ve telafi etme modeli de negatif yönlü ilişkilerde söz konusudur (Mansfield ve Evans, 1975; Rain vd., 1991; Judge ve Wanaabe, 1993). Bu çalışmadaki ilişki yayılma modeline uygundur.

Spor tatmini ile yaşam tatmini arasındaki ilişkileri doğrudan ele alın bir çalışmaya literatürde rastlanmamıştır. Ancak yine yayılma modeline uygun bir ilişki bulunduğu görülmektedir. Sporcular yaşamdaki tatminsizliklerini sporta telafi etmeyi veya spor yaşamı ile sosyal yaşamını birbirinden ayırmayı düşünmemektedir. 
Can, Y. (2016). Sporcuların iş tatmini spor tatmini ve örgütsel bağlılık duygularının yaşam tatmini üzerindeki etkisinin incelenmesi. Journal of Human Sciences, 13(3), 5248-5256. doi:10.14687/ihs.v13i3.4237

Örgütsel bağlılık da yaşam tatminini olumlu etkilemektedir. Bunun en önemli neden yaşam tatminini oluşturan temel unsurlardan birinin de bireyin iş yaşamı olmasıdır. Örgütüne bağlı olan bireylerin yaşamlarından da tatmin olacağı hayret edilecek bir sonuç değildir. Sporcular açısından kulüpleri ile olan ilişkileri onlar açısından büyük önem arz etmektedir. Örneklem dikkate alındığında büyük bir çoğunluğunun sporu bir meslek olarak yapıyor olmaları örgütsel bağlllkk-yaşam tatmini ilişkisinin pozitif yönlü olmasının nedenini gayet iyi açıklamaktadır. Kulübünden tatmin olan bireyler yaşamlarından tatmindirler. Sporu bir hoby olarak gören kişiler açısından kulüp önemli bir anlam ifade etmez iken, özellikle yaşam tatmini açısından, sporu meslek olarak icra edenleraçısından son derece önemlidir.

$\mathrm{Bu}$ çalışma yaşam tatmini düşük bireylerin iş tatminlerinin, spor tatminlerinin ve örgütsel bağlılıklarının da düşük olması nedeniyle yayılma etkisinin ters yönlü olabileceğini göstermiştir. Yapılan t testlerinde iki grup arasında $\mathrm{p}<0.001$ düzeyindeki anlamlı farklılıklar iş tatminini, spor tatmininin ve örgütsel bağlllı̆̆ın sporcular açısından önemini ortaya çıkarmıştır. Genel olarak değerlendirildiğinde bu çalışma yaşam tatmininin nedenlerini ortaya koyması bakımından son derece önemli bir boşluğu doldurmuştur. Bir sporcunun yaşam tatminini etkileyen faktörlerin ortaya çıkarılması antrenörler ve sporcuların kendileri açısından son derece önemlidir.

\section{KAYNAKLAR}

Allen, N. J. and Meyer, J. P. (1990), The Measurement and Antecedents of Affective, Continuance and Normative Commitment to the Organization, Journal of Occupational Psychology, Vol. 63, pp. 1-18.

Diener, E., Emmons, R. A., Larsen, R. J., and Griffin, S. (1985). The satisfaction with life scale. Journal of Personality Assessment, 49, 71-75.

Heller, D.; Judge, T. A. and Watson, D. (2002), The Confounding Role of Personality and Trait Affectivity in The Relationship Between Job and Life Satisfaction, Journal of Organizational Behavior, 23, ss. 815-835.

Judge, T. A., Thoresen, C. J., Bono, J., E., and Patton, G.K. (2001), The job satisfaction-job performance relationship: A qualitative and quantitative review, Psychological Bulletin, Vol: 127, No:3, pp.376-407.

Judge, T. A. and Watanabe, S. (1993). Another look at the job satisfaction-life satisfaction relationship. Journal of Applied Psychology, 78, 939-948.

Krettner, R. and Kinıck1, A. (2004), Organizational Behavior, Sixth Edition, Irwin McGraw Hill, New York.

Locke, E. A. (1976), The Nature and Causes of Job Satisfaction, in Dunette, M. (Ed.), Handbook of Industrial and Organisational Psychology, Consulting Psychologists Press, Palo Alto, CA.

Mansfield, R. and Evans, M.G. (1975) Work and non-work in two occupational groups, Industrial Relations 6: 48-54.

Meyer, J. P. and Allen, N. J. (1984). Testing the "side bet theory" of organizational commitment: Some methodological considerations. Journal of Applied Psychology, 69, 372-378

Meyer, J.P., and Allen, N.J. (1991). A three-component conceptualization of organizational commitment. Human Resource Management Review, 1.

Meyer, J. P. and Herscovitch, L. (2001), Commitment in the Workplace: Toward a General Model, Human Resource Management Review, Vol. 11, pp. 299-326

O'Reilly, C., and Chatman, J. (1996). Cultures as social control: Corporations, cults, and commitment. In L. Cummings, \& B. Staw (Eds.), Research in Organizational Behavior (Vol. 18, pp. 157-200). Greenwich, CT: JAI Press

Rosich, M. M. (1999). Satisfacción de los y de las adolescentes con el deporte. In VII Congreso Nacional de Psicología de la Actividad Física y el Deporte (pp. 173- 181). Murcia: Sociedad Murciana de Psicología de la Actividad Física y del Deporte. 
Can, Y. (2016). Sporcuların iş tatmini spor tatmini ve örgütsel bağlılık duygularının yaşam tatmini üzerindeki etkisinin incelenmesi. Journal of Human Sciences, 13(3), 5248-5256. doi:10.14687/ihs.v13i3.4237

Scanlan, T. K., Carpenter, P. J., Schmidt, G. W., Simons, J. P., and Keeler, B. (1993). An Introduction to the Sport Commitment Model. Journal of Sport \& Exercise Psychology, 15(1), 1 15.

Spector, P.E. (1997). Job Satisfaction: Application, Assessment, Causes, and Consequences. United Kingdom: Sage Publications Ltd.

Warr, P. B., Cook. J . and Wall, T. D. (1979), Scalestor the measurement ofsome work attitudes and aspects of psychological well-being. Journal of Occupational Psychology. 52, 129-14.

Wasti, S. (2002), Affective and Continuance Commitment to the Organization: Test of an Integrated Model in the Turkish Context, International Journal of Intercultural Relations, Vol. 26, pp. 525-550.

\section{Extended English Abstract}

Life satisfaction, which is the main topic of this study, is one of the subjects which has been the center of interest of psychologists, sociologists, organizational behavioral scientists and behavioral scientists. When one refers to life satisfaction, he does not refer to a specific situation but he refers to satisfaction in all areas of life in general. Life satisfaction is a summarized overall evaluation of the ways which one likes or dislikes about his own life (Heller and at all, 2003). In another definition, life satisfaction means the emotional reaction or attitude that one shows to the whole life defined as leisure and non-working time. When evaluated through this point of view, life satisfaction can be seen as an attitude. It is the reaction of the individual to the life. It is the positive difference between the expectations and degree of meeting of those expectations. The confusion of the roles mentioned above is one of the leading factors that directly affect the life satisfaction. The work lives, social lives, their lives with their friends, in short the lives of the individuals within various groups, affect the perception of the individuals concerning life itself and therefore it affects the life satisfaction also.

Job satisfaction is the positive emotions through which the individual achieves in his evaluation regarding his work or work experience (Locke, 1976). In this study, the athlete's job is sports. Therefore, the athletes will have a reaction regarding their work or they will make an evaluation regarding their work and they will reach a positive or negative emotion.

On the other hand, sports satisfaction is a possible satisfaction for only those individuals who do sports. When the athletes are examined, it is understood that the work and the sports satisfaction are different from each other. An athlete may be happy with the task assigned to him in the team; because the work is a concept including the wage, the working conditions, the training conditions, the psychological evaluations and also the appearance of the work from outside. But the sports satisfaction is about the individual himself. These are the general evaluations which show whether the work provided is done well or whether the success is achieved in the given task. The individual may be pleased with his work but may not be satisfied with his game. These two satisfactions may or may not affect each other. Sports satisfaction is the positive emotions concerning the sporting experiences of the athletes within their own areas or areas of interests (Scanlan et al, 1993).

Organizational commitment is a psychological condition that connects the individual to the organization (Meyer and Herscovitch, 2001; Wasti, 2002). Meyer and Allen deals with organizational commitment in three dimensions (Meyer and Allen, 1984, Allen and Meyer, 1990). First dimension is emotional attachment. Emotional attachment is the idea of the individual for staying in the organization because the organization has supported the individual and shown concern for him (Meyer and Allen, 1991). The second dimension is continuity commitment. In this commitment, the individual decides to stay in the organization because he thinks that there are no alternatives on the outside, that the psychological cost of the other alternatives would be high or that economically his revenue would diminish (Meyer and Allen, 1991). The third and final 
Can, Y. (2016). Sporcuların iş tatmini spor tatmini ve örgütsel bağllık duygularının yaşam tatmini üzerindeki etkisinin incelenmesi. Journal of Human Sciences, 13(3), 5248-5256. doi:10.14687/ihs.v13i3.4237

dimension is normative commitment. In this type of commitment, the individual continues to stay in the organization because he thinks that he cannot quit his duty in the organization because of ethical reasons, and that he has to do that work, and that it would not be appropriate if he quits his duty (Meyer and Allen, 1991, Allen and Meyer, 1990). The individuals that means the athletes, who prefer active sportive life in the name of a club-federation or country would desire to stick to their teams with the emotional commitment, continuity and normative commitments. This sense of commitment is an important source of power that balances the athletes' active sports life. Therefore, in every sporty success this feeling of commitment is strengthened and in any case of failure this sense of commitment turns into a harbor which the athlete can take refuge in.

This research has two main purposes. The first is to examine the effect of the athletes' job satisfaction, sports satisfaction and organizational commitment emotions on their life satisfaction. The second is to examine whether there are significant differences between job satisfactions, sports satisfactions and organizational commitments of those athletes who have a low life satisfaction and of those who have a high life satisfaction.

This research was carried out on a total of 669 athletes who were randomly selected from 20 different provinces of Turkey and who voluntarily agreed to participate in the study. Job satisfaction, sports satisfaction, organizational commitment and life satisfaction scales were used as data collection tools in the research.

As a result of the data obtained in the study, it is seen that all three independent variables have an effect on life satisfaction. Job satisfaction-sport satisfaction and organizational commitment account for $43.2 \%$ of life satisfaction together. When Beta coefficients are examined, it is seen that all effects are positive and organizational commitment is the biggest effect. The second fundamental question of the study was whether job satisfaction, sports satisfaction and organizational commitment of the athletes with low and high life satisfaction were different. To do this, the sample was divided into two groups in terms of life satisfaction. Those who have life satisfaction under the middle level and those who have life satisfaction above the middle level are coded separately. Thus, the sample is divided into two groups in terms of life satisfaction.

A significant difference $(p<0.001)$ was found between the job satisfaction feelings of athletes with low life satisfaction and athletes with high life satisfaction. According to that result, the athletes with high life satisfaction have higher job satisfaction feelings when compared to those with low life satisfaction. A significant difference $(p<0.001)$ was found between the sports satisfaction feelings of athletes with low life satisfaction and athletes with high life satisfaction. According to that result, the athletes with high life satisfaction have higher sports satisfaction feelings when compared to those with low life satisfaction.

This study has shown that, individuals with low life satisfaction, have lower job satisfaction, sports satisfaction and organizational commitments and therefore the spillover effects may be inversely related. In the $t$ tests made, the significant $\mathrm{p}<0.001$ level differences between the two groups revealed that job satisfaction, sports satisfaction and organizational commitment are important for the athletes. 